\title{
O deslocamento da prisão em três Comissões Parlamentares de Inquéritos (CPIs) e sua centralidade na conformação de redes criminais transnacionais
}

\author{
Displacement of prison in three Parliamentary Inquiry \\ Committees (CPIs) and its centrality in shaping \\ transnational criminal networks
}

\author{
Camila Nunes Dias* \\ Natália Caruso Theodoro Ribeiro**
}

\section{RESUMO}

Este artigo busca analisar as mudanças ocorridas nas dinâmicas criminais nas duas últimas décadas no Brasil, com base nos relatórios de três Comissões Parlamentares de Inquéritos (CPIs) de temas correlatos: Narcotráfico (1999-2000), Tráfico de Armas (2005-2006) e Sistema Carcerário (2007-2008). Argumentamos que a sequência das três CPIs acompanha a dinâmica própria do fenômeno ocorrido no Brasil, em que as prisões passam a se constituir em hubs criminais. Verificamos que a emergência e expansão dos grupos criminosos de base prisional - que no período transbordam os muros das prisões e assumem a centralidade no debate sobre segurança pública - se refletem no deslocamento da discussão das três CPIs: o foco do debate se desloca dos mercados ilícitos das drogas para as dinâmicas prisionais, evidenciando cada vez mais a importância das redes criminais constituídas nas prisões.

Palavras-chave: Redes criminais transnacionais; Prisões; CPIs.

Professora adjunta da UFABC. Mestre (2005) e doutora (2011) em Sociologia pela Universidade de São Paulo (USP). Também atua como pesquisadora colaboradora do Núcleo de Estudos da Violência (NEV) da Universidade de São Paulo. Líder do Grupo de Pesquisa em Segurança, Violência e Justiça/SEVIJU da UFABC. Email: camila.dias@ufabc.edu.br

** Doutoranda pelo Programa de Pós-Graduação em Ciências Humanas e Sociais da Universidade Federal do ABC e mestre em Ciência Política pela Universidade de Brasília. No momento, é conselheira do Conselho da Comunidade da Comarca de São Paulo e membro do Grupo de Pesquisa em Segurança, Violência e Justiça/SEVIJU da UFABC. E-mail: nctr26@gmail.com 


\begin{abstract}
This article analyzes the changes criminal dynamics have undergone in the last two decades in Brazil, drawing on the findings of three Congressional Investigative Committees (CPI, in Portuguese) on topics related to the matter: Drug Trafficking (1999-2000), Weapons Trafficking (2005-2006), and Prison System (20072008). We argue that the evolution of the 3 CPI's coincides with the dynamics of how prisons became criminal hubs in Brazil. The emergence and expansion of prison-based criminal groups - which have transcended prison walls and have taken the center stage in the public security debate - are noticeable in the evolution of the debate through the three CPIs: the core of the inquiries shifts from the illicit drug markets to prison dynamics, putting the criminal networks formed in prison on the spotlight.
\end{abstract}

Keywords: Transnational criminal networks; Prisons; Congressional Investigative Committees.

\title{
Introdução
}

Este trabalho tem como objetivo analisar as mudanças ocorridas nas dinâmicas criminais no Brasil nas duas últimas décadas, com ênfase no mercado ilegal de drogas ilícitas, tendo como base empírica os relatórios de três CPIs que tratam de temas relacionados ao argumento desenvolvido aqui, correlatos e contíguos: a do Narcotráfico (1999-2000), a do Tráfico de Armas (2005-2006) e a do Sistema Carcerário (2007-2008).

A proposta visa contribuir com o acúmulo de estudos existentes sobre as dinâmicas criminais, em especial, aquelas que apresentam caráter transnacional, apontando a importância da prisão para a organização do crime, notadamente, na articulação de atores e de práticas referidas à economia das drogas (DIAS, 2013; GALLO, 2014; FELTRAN, 2018). A condição de encarcerado oferece aos indivíduos marcados pela trajetória criminal elementos para a construção de uma identidade específica, além de oportunidades para aglutinação de interesses em termos de suas habilidades e experiências individuais em torno de redes, que permitem a potencialização de suas práticas criminais individuais e coletivas. Ademais, a produção de laços sociais baseados nos elementos de identificação oferecidos no cárcere confere estabilidade e previsibilidade às redes criminais de base prisional que, cada vez mais, são protagonistas 
no mercado das drogas ilícitas, principalmente o de cocaína e maconha (PAOLI, 2002, 2017) ${ }^{1}$.

A importância crescente assumida pela economia das drogas no Brasil a partir dos anos 1970 (LEEDS, 2003; MISSE, 1999), as características próprias da atividade de tráfico de drogas (PAOLI, 2017; KENNEY, 2007; DURAN-MARTINEZ, s/d) e a política de encarceramento adotada no país nas últimas décadas (DIAS, 2013; 2017) são elementos que se conectaram e transformaram as dinâmicas ilícitas no Brasil, sendo cruciais para compreender a conformação da prisão como hub de redes criminais. Para contribuir com esse debate, propomos analisar os relatórios finais das três CPIs supramencionadas a fim de, por meio das dinâmicas criminais ali descritas, compreender o deslocamento da prisão para uma posição de centralidade na configuração das redes criminais. Para tanto, buscar-se-á observar as seguintes variáveis: o perfil dos atores investigados e/ou entrevistados, papel que o sistema prisional ocupa nas narrativas e o que dizem sobre as organizações criminosas. Além disso, considerando que cada uma dessas CPIs trata de temas distintos, embora relacionados entre si, pretende-se apontar as conexões entre as dinâmicas criminais abordadas em cada uma delas, bem como delinear continuidades e descontinuidades.

Autores como Salamanca e Salcedo-Albarán (2012) são categóricos em afirmar que, na última década, observou-se uma maior interconectividade entre as diferentes redes de práticas ilegais ao redor do mundo. Este artigo vem a reboque das análises, como a desses autores, cada vez mais consolidado internacionalmente, que busca analisar o fenômeno do "crime organizado"” por meio de uma perspectiva de redes (KENNEY, 2007; JONES et. alli. 2018; SALAMANCA \& SALCEDO-ALBARÁN, 2008; GERDES, 2005; GALLO, 2014). Acompreensão dos processos de criação e de disseminação das re-

1 Importante registrar que as análises aqui propostas em torno do que chamamos de economia das drogas ilícitas se restringem ao comércio de maconha e cocaína (bem como derivados da coca). Tais atividades, muitas vezes, englobam outras mercadorias, inclusive outras substâncias ilícitas, mas, isso não é uma regra. Também é importante notar que há comércio ilegal de drogas legais, bem como outras modalidades de drogas ilícitas que, em geral, tem uma dinâmica diferente e, portanto, optou-se por não as abordar neste texto. Caso interesse, sobre o tráfico de drogas sintéticas no Rio de Janeiro, ver Grillo (2008).

2 A despeito da vasta literatura em torno do "crime organizado" - na qual as posições sobre a sua insuficiência, a ausência de adequação ou mesmo sobre os equívocos que provoca são bastante numerosas - neste texto utilizaremos como sinônimo de redes criminosas organizadas, sem a pretensão de atrelar ao conceito um significado específico ou de nos posicionarmos neste debate. Para o debate sobre o uso da expressão "crime organizado", ver: Albini (1997); Rogovin \& Martens (1997); Paoli (2002); Zaffaroni (1996). 
des criminais a partir do sistema prisional coloca este projeto em diálogo estreito com os debates sobre os efeitos produzidos pelas políticas públicas de segurança centradas no encarceramento (DIAS, 2017; VASCONCELOS, CARDOZO, PEREIRA \& DE VITTO, 2018).

Construindo o recorte da análise a partir do deslocamento da posição da prisão nos três momentos representados pelas referidas CPIs, objetiva-se propor algumas reflexões sobre a intersecção da prisão com as dinâmicas criminais organizadas, notadamente, o circuito no qual as "facções" são protagonistas na construção, no fortalecimento e expansão de "redes criminais" que se constituem com base na prisão e que, nesse processo, assumem também uma dimensão global, sobretudo pela conexão com outras redes criminais de caráter transnacional.

\section{As Comissões Parlamentares de Inquérito}

CPIs são institutos de competência do Legislativo que, a fim de realizar os seus trabalhos, detêm algumas prerrogativas típicas de autoridades judiciais. São elas: ouvir testemunhas e indiciados, podendo recorrer à condução coercitiva; quebra de sigilo bancário fiscal e telefônico; requisitar informações e documentos de repartições públicas e autarquias; determinar diligências. Todas as prerrogativas de uma CPI pertencem ao colegiado. Isso significa que apenas com o voto da maioria é que se pode determinar seu uso, sendo que nenhum membro, individualmente, dispõe dessas prerrogativas. O produto final do trabalho da CPI, via de regra, é um relatório com suas conclusões. Além de um resumo da documentação coletada e das atividades, o relatório pode apresentar um projeto de lei. É importante salientar que não é função da CPI julgar, e nem esta tem poder de punir. Seu relatório deve ser remetido, via de regra, ao Ministério Público para que se promova a responsabilização, civil e/ou criminal dos indiciados (BRASIL, 1952). Isto é, a decisão de responsabilização cabe ao Ministério Público, não à Comissão da CPI.

Como pode se deduzir de seus nomes, as CPIs aqui em análise versam sobre assuntos que encontram alguma relação com dinâmicas criminais. Em todas, observou-se que são recorrentes algumas temáticas: tráfico de drogas e de armas, organizações criminosas e/ou redes criminais - dos mais diversos tamanhos e formatos - atuantes em alguma das tantas etapas ou atividades 
dos mercados ilícitos. É notório que, em menos de uma década ${ }^{3}$, ocorreram mudanças sensíveis nas dinâmicas criminais, algumas destas possíveis de se depreender da leitura dos relatórios dessas Comissões. Entre as mudanças observadas, destacamos o deslocamento do papel ocupado pela prisão, que passa de uma posição periférica na CPI do Narcotráfico para o foco central da própria investigação parlamentar na CPI do sistema carcerário ${ }^{4}$. Para melhor compreender esse deslocamento, a seguir, trataremos de cada uma das CPIs separadamente.

\section{CPI do Narcotráfico}

Requerida no início de fevereiro de 1999, a "CPI do Narcotráfico" - cuja atribuição formal foi a investigação sobre o avanço e a impunidade do narcotráfico - foi instalada no dia 13 de abril daquele ano. Em seu documento inicial, trazia como justificativa de sua abertura dados "alarmantes", como o de que 25\% dos jovens entre 10 e 18 anos já tinham utilizado alguma droga ilegal e de existir cerca de 2 milhões de usuários de entorpecentes no país ${ }^{5}$. Afirmava, portanto, que o narcotráfico relacionava-se a crimes de toda a espécie, nominando, todavia, apenas a prostituição.

Para melhor contextualizar, cabe lembrar que a década de 1990 foi marcada pela instauração de uma série de CPIs que antecedeu à do Narcotráfico: a do Judiciário (1999), do PC Farias (1992) e dos Anões do Orçamento (1993). O contexto marcado pela recente experiência de eleições diretas para presidente - seguida do que seria o primeiro caso de impeachment ${ }^{6}$ na história do país - fará com que, em comum, essas CPIs tenham como seu fulcro a preocupação com a corrupção dos agentes de Estado. Assim, apesar de, em sua justificativa, a CPI do Narcotráfico afirmar que sua preocupação deriva de um problema "social”, veremos que suas investigações atentam-se para a

3 Especificamente entre 1999 e 2008, período que compreende o início da primeira e o término da terceira CPI.

4 Obviamente, esse deslocamento não pode ser analisado desconsiderando-se o foco específico de cada uma das investigações. Apesar disso, como discutido no decorrer do texto, é possível observar articulações, continuidades e deslocamentos.

5 Esses números, destoam de uma das mais importantes pesquisas na época: segundo relatório da agência da Organização das Nações Unidas para Drogas e Crime (UNODC), o total da população brasileira que consumia maconha e cocaína no início dos anos 2000 era menor: respectivamente, 6,9\% e 2,3\% (UNODC, 2005).

6 A CPI de 1992, no caso, está diretamente relacionada ao impeachment. 
corrupção de agentes estatais. Isso significa que há uma relação de continuidade com as investigações encabeçadas pelas CPIs do período.

Segundo Rodrigues (2002), a CPI do Narcotráfico foi precedida de outra CPI, ocorrida em 1991, que buscou investigar a relação de deputados e juízes com o tráfico de drogas. Resultou na destituição do cargo o deputado Federal Jabes Rabelo, por manter relações com traficantes de seu Estado, Roraima ${ }^{7}$. Em 1996, é a vez de o Acre ser pauta parlamentar, por causa do deputado Hildebrando Pascoal (PFL-AC) ${ }^{8}$ - acusado de comandar um grupo de extermínio a serviço de traficantes. Além dessa acusação, o nome do parlamentar apareceu relacionado ao narcotráfico em outra investigação, sobre o ex-governador do Acre, Orleir Cameli (1995-1998). De acordo com Rodrigues (2002), esses teriam sido os eventos que precederam a instauração da CPI do Narcotráfico. De fato, observa-se no relatório - que é organizado por unidades da federação - uma especial atenção ao Acre, especialmente, aos casos relacionados ao ex-deputado Hildebrando Pascoal.

A análise de Gallo (2014) aponta que os casos investigados pela CPI do Narcotráfico privilegiaram a descrição de organizações de pessoas, de rotas de transporte e fluxos de negócios do comércio da droga. Nesse sentido, os atores situados nas duas extremidades da rede, isto é, os vinculados ao comércio da droga para o consumidor final e os que atuam na produção e no comércio em grande escala aparecem desempenhando papéis secundários em relação às organizações e aos personagens evidenciados na trama relatada pela CPI.

No Acre, em Alagoas e no Espírito Santo, o relatório da CPI teve como foco o envolvimento de políticos em negócios ilegais (armas, drogas, extração de madeira, etc.), contando ainda com a atuação direta de policiais por

7 Rodrigues (2002) afirma que Rabelo foi eleito pelo Acre, contudo, ao checar a base de dados da Câmara, constata-se que este foi eleito por Roraima. Em maio de 1991, o deputado foi acusado de envolvimento com o tráfico de drogas. Em julho do mesmo ano, seus irmãos Abidiel e Noabias Pinto Rabelo (com quem o deputado tinha uma série de empresas, incluindo uma transportadora) foram presos em São Paulo com um carregamento de 554 quilos de cocaína, sendo encontrado com o primeiro uma carteira falsa de assessor parlamentar da Câmara dos Deputados, assinada por Jabes. Por esta falsificação, foi afastado do cargo em novembro de 1991. Fonte: http://www.fgv.br/CPDOC/BUSCA/dicionarios/ verbete-biografico/jabes-pinto-rabelo

8 Ex-coronel da Polícia Militar e ex-deputado Estadual (1995-1999), e brevemente Federal (1999), Hildebrando Pascoal ficou conhecido como "deputado motosserra" por matar e esquartejar seus desafetos. Foi preso em 1999 e sentenciado a 100 de prisão pelos crimes de homicídio, tráfico de drogas e lavagem de dinheiro. Para uma análise desse caso, sugerimos a leitura de Possas \& Rocha (2014). 
meio de grupos de extermínio. No caso do Espírito Santo, é importante destacar a descrição da dinâmica do tráfico de drogas internacional ao tratar de traficantes que estavam presos por tentarem embarcar para a Holanda com 650kg de cocaína no Porto de Capuaba, em Vila Velha. Contudo, apesar de presos, eles continuariam mantendo seus negócios por meio de celulares e outras "regalias", não especificadas nos relatórios. Essa passagem é importante para situar a prisão como espaço no qual negócios ilegais têm continuidade. Nesse caso, trata-se da manutenção das atividades econômicas ilegais nas quais esses indivíduos estavam inseridos antes de serem presos e cuja continuidade está ligada à então recente emergência dos aparelhos de telefones celulares - na época, com acesso ainda bastante limitado e restrito à pessoas específicas.

Ainda no caso do Espírito Santo, outro caso de destaque é a relação do grupo de extermínio denominado "Scuderie Detetive Le Cocq" que, além da prática de mortes e extorsões, teria um "acordo de conveniência” com uma figura bastante conhecida no "mundo do crime" e das organizações criminais brasileiras: Luís Fernando da Costa, conhecido como Fernandinho Beira-Mar. No relatório da CPI, ele foi acusado de lavagem de dinheiro em Guarapari (ES), por meio de investimentos em construções e, a partir dessas atividades, teria engendrado um esquema de favorecimento a grupos criminais locais.

Entretanto é na subseção do Rio de Janeiro que a figura de Beira-Mar assume centralidade nas dinâmicas descritas no relatório da CPI. Importante registrar a importância que as mulheres assumem nesses relatos. Todas elas, de algum modo, teriam se envolvido afetivamente com Fernando ou seriam familiares de pessoas da organização que atuariam na operação cuidando da parte financeira - seja como tesoureiras, como transportadoras de valores ou como donas de "fachadas" para bens adquiridos com o dinheiro do tráfico. O relatório afirma, então, a posição de independência de Fernandinho Beira-Mar em relação aos “Comandos”,, - comercializando drogas ${ }^{10}$ com qualquer

9 Entende-se aqui: Comando Vermelho, Terceiro Comando ou qualquer outro grupo do Rio de Janeiro que, já na época, era conhecido do público e das autoridades.

10 Sobre a rota da droga: Alda afirma que que vinha do Paraguai, via Cidade do Leste, passando pela Ponte da Amizade, para Foz do Iguaçú; depois, seguia pela Via Dutra, no mesmo roteiro que os ônibus de passageiros de turismo. Fernandinho Beira-Mar recebia a droga vinda da Colômbia, acreditando ela ser a droga oriunda do Cartel de Medellín. Informou que a droga remetida para o exterior é realizada a partir do Paraguai, sem ingressar no território brasileiro. Ela afirmou que não sabia bem como funcionava o esquema de remessa para o exterior, mas sabia que Fernandinho Beira-Mar remetia a droga para a Suíça. 
um que tivesse condições de pagar, de modo que os entorpecentes que vendia eram embalados e etiquetados com a expressão "Facção Fernando" ou "Facção Costa”. A participação dos policiais é narrada na maior parte das vezes, não como protagonistas, mas como operadores beneficiários principalmente por meio de extorsões - diferentemente, portanto, dos casos relacionados ao Espírito Santo. Observa-se que a “organização criminosa” - descrita como tal no relatório da CPI - é constituída de pessoas portadoras de laços fortes de confiança, sobretudo parentes e amigos que servem de "testa de ferro" em diversas empresas de fachada para lavagem de dinheiro.

A respeito deste caso, é importante pontuar a importância deste ator no cenário nacional do comércio de drogas ilícitas. Fernandinho Beira-Mar é considerado um precursor das dinâmicas contemporâneas do tráfico de drogas no Brasil (MANSO \& DIAS, 2018). Ele foi pioneiro no processo de aproximação entre os atores criminais do Sudeste, vinculados aos grupos de base prisional, aos das fronteiras brasileiras, para reduzir o número de intermediários nos esquemas de comércio de drogas, aumentando os lucros (MANSO \& DIAS, 2018).

É importante destacar também que a descrição contida no relatório da CPI corrobora com o argumento que vem sendo desenvolvido em outros trabalhos (MANSO \& DIAS, 2018) sobre as diferenças da atuação entre CV e PCC, em termos da relação entre o "coletivo" - o Comando - e o individual, seus integrantes. A atuação do "CV" nas regiões de fronteira e nos países vizinhos decorre da atuação do grupo que trabalhava diretamente com Fernandinho Beira-Mar. Porém, não se trata do CV - enquanto coletivo de base prisional e portador de normas e regras coletivas de comercialização e de comportamento - e, sim, da quadrilha de Beira-Mar, muito diferente da atuação do PCC, como veremos mais adiante.

Como já mencionado, as investigações ocorridas nesta CPI parecem claramente privilegiar o envolvimento de agentes públicos nas suas mais variadas posições e não só aqueles que se encontram nas franjas das redes criminais. É importante notar a descrição de múltiplas redes criminais localmente constituídas. Nesses casos, elas foram observadas a partir das lentes territoriais que organizaram o material e a própria investigação que seguiu uma lógica de recorte por Estados - embora o próprio relatório tenha apontado os vários pontos de contato e vínculos das redes umas com as outras. 
Portanto, a segmentação estadual que predomina no relatório é mais decorrente da lógica de coleta e de organização da exposição das informações do que das dinâmicas criminais analisadas em si mesmas. As dinâmicas analisadas apresentavam um caráter eminentemente interestadual e transnacional. Para reduzir o impacto do recorte territorial escolhido e expor as dinâmicas que apresentam-se a partir de fluxos diversos, o relatório da CPI trouxe subseções que evidenciam essa dimensão essencial do Narcotráfico, privilegiando descrever o fluxo de movimentação das redes e seu pontos de conexão ${ }^{11}$. Outrossim, descreve inúmeros esquemas transnacionais envolvendo, principalmente, os Estados fronteiriços do Arco Central do Brasil ${ }^{12}$.

\section{CPI do Tráfico de Armas}

Instaurada no dia três de março de 2005, a CPI do tráfico de armas seguiu um caminho diferente do tradicional. Como havia vários outros pedidos de CPI esperando na fila, os deputados decidiram levar o projeto diretamente para a aprovação em plenário, sem depender do recolhimento de assinaturas, para que tivesse preferência sobre os demais (FOLHA, 2005). Como justificativa de sua instauração, o texto do projeto menciona o fato de os Estados e Municípios se encontrarem "inertes e impossibilitados operacionalmente de restabelecer a ordem nos centros urbanos".

A afirmação sobre a questão da segurança nas metrópoles é demasiadamente vaga para nos fornecer pistas de quais outras motivações acarretaram no agendamento da CPI. No entanto, ao recorrer aos noticiários da imprensa para reconstruir a conjuntura na qual esse processo se deu, nos deparamos com uma multiplicidade de "crises" urbanas relacionadas ao sistema prisional, especialmente no Rio de Janeiro e em São Paulo.

Vários episódios ocorridos desde o fim da CPI do Narcotráfico (2000) e o início da CPI do Tráfico de Armas (2005) posicionavam as chamadas facções prisionais como atores relevantes nas dinâmicas criminais do país, com destaque

11 São cinco as principais conexões descritas, cada uma em uma subseção: a Conexão Suriname, a Africana, a Nigeriana, a Conexão Paraguai e a Goiana (que envolvia esquema de lavagem de dinheiro de supostos integrantes de cartéis colombianos),

12 A base territorial das ações do Governo Federal para a região de Fronteira estabelece como áreas de planejamento três grandes Arcos, que foram definidos com base na proposta de reestruturação do Programa de Desenvolvimento da Faixa de Fronteira (2005): o sul, o norte e o central. Este último, tratado neste caso, compreende as regiões de fronteira dos Estados de Rondônia, Mato Grosso e Mato Grosso do Sul (BRASIL, 2009). 
para o então emergente grupo paulista, Primeiro Comando da Capital (PCC). O PCC foi criado em 1993 dentro de unidades prisionais paulistas e ficou conhecido nacionalmente no ano de 2001 após promover o evento que ficou conhecido como Primeira Megarrebelião do Sistema Prisional brasileiro, onde 29 unidades prisionais de São Paulo se rebelaram simultaneamente (ADORNO \& SALLA, 2007; DIAS, 2013; SALLA, 2003; 2006; 2007). Entre 2002 e 2003, o PCC esteve presente no noticiário nacional em razão de diversas ações atribuídas ao grupo - sequestros, roubos, rebeliões, ataques a órgãos públicos ${ }^{13}$.

Além disso, em março de 2003, ocorrera o assassinato do juiz responsável pela execução penal no presídio no qual se encontrava presa a cúpula do PCC e também Fernandinho Beira-Mar ${ }^{14}$. Acusada de ser responsável pelo homicídio, esse episódio revelava de forma contundente a capacidade da facção paulista de praticar ações articuladas fora das prisões, mas planejadas de dentro delas. Quatro meses depois desse episódio, quinze integrantes da facção foram presos com um arsenal de guerra: cinco submetralhadoras, cinco fuzis, seis pistolas automáticas, dois revólveres e três granadas (MAGALHÃES, 2004).

Interessante notar que, na CPI do Narcotráfico, finalizada apenas cinco anos antes de ser iniciada a do Tráfico de Armas, sequer se menciona a sigla PCC. A presença do PCC no noticiário e na opinião pública de forma geral foi crescendo de maneira significativa durante a década de 2000 (ADORNO \& DIAS, 2016). Nota-se uma profunda mudança na dinâmica criminal, sobretudo em São Paulo, no período entre as duas CPIs. Não é de se espantar, por conseguinte, a centralidade que o PCC adquire nos trabalhos da CPI do Tráfico de Armas. Essa centralidade se intensifica no final da CPI quando ocorre o evento que ficou conhecido como "Ataques de maio de 2006" (ADORNO \& SALLA, 2007; ADORNO \& DIAS, 2016).

Diferentemente da CPI do Narcotráfico, pouco se mencionou nomes de políticos envolvidos diretamente nas redes criminais. Muito embora admita-se que a conivência das autoridades e corrupção de agentes públicos nas fronteiras seja fundamental para o tráfico de armas, bem como o desvios de armas dos lotes das agências públicas, praticamente não há acusações explícitas a nenhum ator estatal de alto escalão ${ }^{15}$.

13 Ver, por exemplo: https://www1.folha.uol.com.br/fsp/cotidian/ff1301200604.htm

14 https://www.terra.com.br/noticias/brasil/policia/testemunhas-assassinato-de-juiz-foiordem-do-pcc,f54f6ce675e4b310VgnCLD200000bbcceb0aRCRD.html

15 As únicas exceções foram os Deputados federais Jorge Salomão e Frederico Antunes. 
Ainda que os depoimentos na CPI do Tráfico de Armas tenham discutido muitas questões, para fins analíticos, podemos agrupá-las em torno de duas temáticas: a primeira gira em torno das fragilidades de fiscalização do tráfico de armas, sobretudo, no que concerne à entrada desse arsenal no país; a segunda é o próprio PCC, questão tratada majoritariamente nos depoimentos de autoridades paulistas (promotores, policiais, secretários) e do depoimento de presos acusados de pertencer ao grupo.

O relatório final afirma que as fronteiras com o Paraguai, a Bolívia e a Colômbia são as principais portas de entrada de armas para o Brasil. De fato, a dificuldade de controle das fronteiras secas nacionais, que, além de vasta, faz divisa com quase todos os países do continente, foi uma questão recorrente nos depoimentos sobre os impasses no controle da entrada de de armas ${ }^{16}$. Ausência de efetivo e fiscalização do Exército e da Polícia Federal, bem como a conivência das autoridades e a corrupção de agentes públicos nas fronteiras brasileiras são apontadas como grandes desafios. Além de São Paulo - a partir da investigação sobre a atuação do PCC -, o Rio Grande do Sul também está entre os locais que receberam uma maior atenção desta CPI, especialmente, a região da fronteira entre Brasil e Uruguai. De acordo com as investigações, tratava-se de uma das principais portas de entrada de armas para o Brasil.

O depoimento de Luiz Fernando Ferreira Delazari - então secretário de Segurança Pública do Paraná - vai ao encontro do campo de debates em torno dos problemas dos fluxos transnacionais e da sobreposição de mercados ilícitos (DURÁN-MARTÍNEZ, s/d; KENNEY, 2007; GLENNY, 2008; SAVIANI; 2013; FORGIONE; 2011). O secretário afirma que os crimes de tráfico de armas e de drogas são complementares e se apoiam mutuamente. Segundo ele, muitas vezes, ocorre a troca de armas por drogas na região de fronteira, o que explicaria por que armas de fabricação brasileira são contrabandeadas no Paraguai. O lago surgido da construção da Usina de Itaipu seria um sério complicador para a repressão dessa modalidade criminosa, pois é facilmente atravessado por pequenos barcos.

De fato, a afirmação feita pelo secretário coaduna-se com que diz a literatura. No debate sobre redes criminais, é quase consensual que a especializa-

16 Apesar das fronteiras se apresentarem como um impasse, depoimentos no relatório indicam que entre $80 \%$ a $90 \%$ das armas ilegais comercializadas no país seriam de origem nacional. Ou seja, o Brasil se posiciona como mercado produtor e consumidor, ao mesmo tempo, nessa economia internacional ilegal. 
ção em produtos específicos do comércio ilícito tem dado lugar à construção de redes que atuam nos mais diversos segmentos e, de forma modular e flexível, se organizam e têm suas funções divididas em termos do tipo de atividade - fornecedores, produção, transporte, armazenamento, recrutamento de colaboradores, etc. - e não do produto (SAVIANO, 2014; FORGIONE, 2011; MAZUR, 2011). Isso quer dizer que arte significativa de atores e redes criminais atua tanto no comércio de drogas quanto no comércio de armas, especialmente, aqueles cujas atividades se situam no nível intermediário das etapas que constituem as economias criminais, isto é, nem no topo da cadeia (produção, fornecimento no atacado), nem na ponta (venda e uso no varejo): notadamente, as atividades de armazenamento, transporte e distribuição oferecem oportunidades de maximização dos lucros ao utilizarem o arcabouço existente em termos de recursos - pessoais e infraestrutura, como veículos, tecnologia, entre outros (NAÍM, 2005; GRILLO, 2012).

No que concerne às drogas e às armas, o vínculo é ainda mais forte em decorrência dos mercados de proteção que são desdobramentos diretos do caráter ilícito das mercadorias comercializadas (MISSE, 1999; GRILLO, 2013; ZALUAR, 2011) e, também, da construção de mecanismos informais de resolução de eventuais conflitos. A violência, na sua forma direta ou indireta, ou mesmo apenas a possibilidade presente de utilizá-la, constitui-se como um recurso fundamental na dinâmica da economia criminal e uma forma de comunicação entre os atores inseridos nessas dinâmicas, embora não seja um produto primário ou consista no objetivo principal das redes criminais (GAMBETTA, 2009).

Em relação às investigações que tiveram como foco o PCC, destacam-se os depoimentos de "Geleião", conhecido por ser um dos fundadores do PCC, expulso da organização em 2002, que fez delação e até hoje cumpre pena em presídios de seguro por estar ainda jurado de morte (DIAS, 2011b); e o depoimento de Marcola que - mesmo negando a posição de "líder" do PCC que lhe é imputada pelas autoridades - descreve os princípios normativos e ideológicos na qual está assentada a base de legitimação reivindicada pelo PCC.

Ainda que haja uma lógica na relação entre tráfico de armas e uma organização criminosa como o PCC, a explicação para a atenção atribuída pela Comissão à organização, definitivamente, ancora-se em importantes eventos que eclodiram durante a CPI, acabando por impor alguns direcionamentos nas investigações. Naquele ano, ocorreu o evento que ficou internacio- 
nalmente conhecido por “Ataques de Maio de 2006”. A transferência de 764 presos de vários presídios paulistas para a Penitenciária de Presidente Venceslau é apontada como o estopim ${ }^{17}$ para a série de eventos. No dia seguinte à transferência, iniciou-se uma série de rebeliões e atentados - sobretudo em quartéis, delegacias e bases policiais -, além de incêndio de veículos e agências bancárias. Jornais apontam que, apenas em São Paulo, os ataques são responsáveis pelas mortes de 564 pessoas (ADORNO \& SALLA, 2006; ADORNO \& DIAS, 2017) ${ }^{18}$. Esses acontecimentos se articularam com episódios da CPI já que, no mesmo período, um depoimento sigiloso do então diretor do DEIC (Departamento de Investigações contra o Crime Organizado) teria sido vazado por meio do pagamento de $\mathrm{R} \$ 200,00$, feito pelos advogados de Marcola, Sérgio Wesley da Cunha e Maria Cristina de Souza Rachado ao técnico de som da Câmara ${ }^{19}$.

Ademais, as investigações preliminares da polícia demonstraram que os eventos foram planejados e orquestrados de dentro dos estabelecimentos prisionais. O principal instrumento de comunicação utilizado foi o telefone celular (ADORNO \& SALLA, 2007). Em decorrência desses acontecimentos, a CPI convergiu seus esforços ainda mais fortemente para o PCC e passou a convocar especialistas em sinal de telefonia celular para discutir as questões técnicas e políticas do bloqueio de sinais celulares nos presídios, chegando inclusive a solicitar medidas judiciais para o bloqueio imediato de celulares nas proximidades dos presídios. Esses dados estavam principalmente contidos no relatório do deputado Julio Semeghini (PSDB-SP), que focava na fragilidade da segurança nos presídios, principalmente em relação à comunicação via celulares e rádios transmissores. A CPI reconhecia que o combate às atividades de uma importante organização criminosa do país passava

17 Estudo de 2011 da International Human Rights Clinic (IHRC), da Universidade de Direito de Harvard, aponta que as rebeliões não se deram somente em razão das transferências: a corrupção no sistema e o descaso com a execução penal no estado também contribuíram para os ataques.

18 Na concepção dos movimentos sociais, contudo, o evento é reconhecido como "crimes de maio de 2006”, em alusão às centenas de pessoas que foram mortas pela polícia no movimento de reação, resposta ou retaliação aos ataques promovidos pelo PCC aos agentes públicos (MÃES DE MAIO, 2011)

19 No dia 10 de maio de 2006, mesma data de início dos "crimes de maio", foram tomados os depoimentos dos delegados do DEIC-SP Godofredo Bittencourt Filho e Ruy Ferraz Fontes, realizado em sessão reservada da CPI do Tráfico de Armas. Soube-se, posteriormente, como relata o próprio relatório desta CPI e fora amplamente divulgado pelos noticiários na época que gravações destas sessões reservadas foram vendidas no mesmo dia por um técnico de som da Câmara dos Deputados, pressionado por dois advogados. 
pela utilização de sistemas de bloqueadores de celulares, admitindo, dessa maneira, que esses atores operavam de dentro do sistema prisional.

\section{CPI do Sistema Carcerário}

Requerida pelo deputado Federal Domingos Dutra (ex-PT-MA), o documento final da CPI do Sistema Carcerário apresentou como justificativa para sua instauração as frequentes rebeliões e motins, bem como a sistemática violação dos direitos e garantias dos presos, contrariando as previsões da Lei de Execução Penal. Devido a esse quadro, o relatório da CPI afirma que seu objetivo era apurar a situação da questão prisional no país e apontar soluções para a humanização do sistema. No decorrer do texto, contudo, nota-se que a questão da corrupção entre os agentes de Estado, sobretudo aqueles casos noticiados pelos meios de comunicação, também foi um fator que motivou a abertura da CPI. O relatório final afirma que notícias como a fuga da traficante "Maria do Pó”20 também teriam incentivado a realização da CPI.

Não se pode esquecer, ademais, os impactos nacionais causados pela crise prisional paulista escancarada em 2006 e que ainda reverberava em várias direções. Ainda durante o curso da CPI do Tráfico de Armas, os ataques evidenciaram que a situação prisional era uma panela de pressão que não poderia ser mais ignorada e estava diretamente articulada com as dinâmicas criminais que ocorriam fora das prisões. Após 2006, ainda, verificou-se um processo de nacionalização do PCC, do CV, bem como o surgimento de outras facções em prisões de vários Estados (MANSO \& DIAS, 2018). Observa-se que os efeitos dos conflitos originados nas prisões já transbordavam para fora das paredes dos presídios, colocando o sistema carcerário no centro dos debates sobre "segurança pública".

Instaurada no dia 22 de julho de 2007, a CPI do Sistema Carcerário durou cerca de oito meses, chegando a fazer diligências em dezoito Unidades da Federação. Nas audiências públicas, concentrou-se em ouvir autoridades federais e estaduais, especialistas, pesquisadores, jornalistas, policiais e representantes da sociedade civil. Diferentemente das demais CPIs analisadas, as diligências da Comissão não estavam centradas em escutar atores investigados. Até mesmo porque o intuito do Relatório foi, antes de mais nada, des-

20 Já citada na CPI do Narcotráfico. 
crever o estado das coisas do sistema penitenciário brasileiro, apresentando um diagnóstico das prisões no país.

O Relatório é subdividido em onze capítulos. O segundo capítulo discute os problemas do crime e destina uma seção para tratar da presença das organizações criminosas dentro dos presídios. Elenca nominalmente diferentes organizações criminosas que atuam no país, mas foca, sobretudo, no PCC. Busca descrever sua estrutura organizacional e reconhece que a atuação da organização já ultrapassou os limites dos estabelecimentos penais e, até mesmo, do Estado de São Paulo. Ademais, reconhece que a corrupção dos agentes de Estado é um fator para o fortalecimento das organizações e que, inclusive, a maioria da entrada de armas, drogas e aparelhos celulares (reconhecidos como armas nas mãos das organizações criminosas) ocorre por meio de agentes públicos.

O quarto capítulo apresenta um resumo das diligências realizadas, separado por Unidade da Federação e estabelecimento penal onde foram realizadas visitas pela comissão ${ }^{21}$. As narrativas, via de regra, trazem denúncias sobre a precariedade da situação dos presos, tratando desde a superlotação à falta de assistência material e jurídica. O relatório pontuou, em diferentes Estados, a presença das organizações criminosas nos presídios. A falta de assistência pelo Estado é apontada como motivação dos presos para integrarem as facções. O relatório reconhece e evidencia o controle dessas organizações sobre a massa carcerária.

Ao final do relatório, ao contrário das demais CPIs, nenhum indivíduo foi indiciado. Foram responsabilizadas, nos entanto, as dezoito Unidades da Federação diligenciadas - Minas Gerais, Rio Grande do Sul, Mato Grosso do Sul, São Paulo, Rio de Janeiro, Bahia, Paraná, Pernambuco, Pará, Ceará, Piauí, Maranhão, Goiás, Rondônia, Mato Grosso, Santa Catarina, Espírito Santo e o Distrito Federal - em razão de a Comissão entender que, em todas, havia omissão em relação ao cumprimento das normas aplicáveis em termos dos direitos dos presos

21 Ao todo, sessenta estabelecimentos foram visitados. 


\section{A centralidade da prisão na configuração de redes crimi- nais transnacionais: o deslocamento entre as CPIs}

A análise das três CPIs permite perceber a emergência de uma nova dinâmica criminal que envolve novos atores conectados entre si por meio de laços de confiança cuja base se altera e que tem na prisão um hub de recrutamento e articulação de pessoas. Enquanto as facções assumem protagonismo na CPI do Tráfico de Armas e também na CPI do Sistema Carcerário - da qual elas são um dos elementos que levou à própria criação da CPI - , esta temática é quase inexistente na CPI do Narcotráfico. Podemos perceber muitas diferenças nas redes criminais que são descritas como protagonistas em cada uma das investigações.

De acordo com Salamanca e Salcedo-Albarán (2016), nem todas as pessoas envolvidas nas redes criminais são “criminosos de carreira” no sentido de ter na atividade ilícita sua principal atividade econômica ( chamados por eles de atores "escuros”). As redes criminais são compostas, também, de atores que estão vinculados a atividades lícitas - são eles políticos, banqueiros, legisladores, servidores públicos e investidores. Esses atores, intitulados por eles de "cinzentos”, são responsáveis por conectar recursos legais e ilegais. (SALAMANCA \& SALCEDO-ALBARÁN, 2012).

Na CPI do Narcotráfico, o foco está nos atores situados nos estratos mais altos da sociedade (deputados, policiais, delegados, juízes, empresários) que, nos termos de Salamanca e Salcedo-Albarán (2012), são chamados de atores "cinza” nas redes criminais. Nesta primeira CPI aqui analisada, são quase inexistentes as narrativas de atores que operam de dentro da prisão. Nos casos em que essa articulação apareceu, essas atividades são descritas como produto de regalias de indivíduos com alto poder econômico para corrupção de agentes públicos.

A CPI do Tráfico de Armas, por sua vez, ao dar centralidade para organizações como CV e PCC, desloca a atenção dos atores cinzas para focar nos “escuros”. A configuração desses grupos, por seu turno, não fica completamente abstrata, buscando-se apontar alguns atores, de modo nominal, como líderes dessas organizações. Observa-se aqui uma análise do fenômeno que se baseia numa separação entre "o mundo do crime" e o "Estado", atribuindo pouca atenção para os nodos conectores dessas duas instâncias.

Muito embora outras facções sejam mencionadas, indubitavelmente, o enfoque da CPI das Armas está no PCC. Evidência disto é que maior par- 
te dos indiciados tem alguma relação direta ou indireta com o PCC, isto é, como membros da organização ("escuros") ou como agentes "cinzas" na conceitualização aqui empregada, cujas práticas são tidas como irregulares e situadas numa zona nebulosa, caso, por exemplo, dos advogados.

Entre a primeira e a segunda CPI analisadas, não houve apenas um deslocamento do foco em termos do produto ilícito comercializado - como fica evidente no nome das duas CPIs - mas, nas redes que foram priorizadas nas duas investigações, as posições dos atores sobre os quais as investigações foram direcionadas (PERALVA, SINHORETTO \& GALLO, 2010). A CPI do Tráfico de Armas se distanciou substancialmente do foco sobre os agentes públicos que pode ser percebido na CPI do Narcotráfico. Há, tanto na CPI do Tráfico de Armas quanto na do sistema Carcerário, claramente, a narrativa de atores que operam as redes criminais a partir do sistema prisional. Além do uso dos celulares, os advogados emergem como peças-chave para o êxito de suas operações.

No caso da CPI do Sistema Carcerário, há uma mudança de foco na direção de apontar a precariedade dos estabelecimentos, mas, reconhece-se que essa situação facilita e propicia as condições para a emergência e o fortalecimento das organizações criminais que atuam dentro das prisões - aqui já conhecida e reconhecida como um problema per se (DIAS, 2013; DIAS, 2017). Apesar de não ter como foco as próprias facções, ainda assim, busca traçar como elas funcionam e, mais uma vez, coloca os celulares e os esquemas de corrupção como fundamentais para o fortalecimento das organizações criminais dentro das prisões.

Importante ressaltar a centralidade assumida pela questão das facções, especialmente, do PCC, para compreender as continuidades entre essas investigações - ainda que, à primeira vista, elas tratem de temas distintos. Em 2007, quando a CPI do Sistema Carcerário foi instalada, as facções já eram reconhecidas como um problema e as prisões já eram percebidas como focos de onde irradiavam tensões, conflitos e violências que ultrapassavam seus muros e produziam efeitos nas dinâmicas criminais e sociais de vários Estados brasileiros (DIAS, 2017; MANSO \& DIAS, 2017; 2018; PAIVA, 2019). Nesse sentido, a CPI do Sistema Carcerário reflete a emergência da percepção das prisões brasileiras como espaços de produção de violências, dotados de grande capacidade de desencadear crises sociais e políticas e nos quais era necessária a intervenção estatal para reduzir as condições que eram propícias para o surgimento e o enraizamento de grupos criminais. 
Desse modo, a sequência e o reduzido lapso de tempo existente entre as três CPIs nos permitem compreender o deslocamento que as prisões assumem no debate público sobre a criminalidade organizada no Brasil.

O efeito criminógeno da prisão já foi amplamente explorado na literatura. Contudo, o fenômeno que se constituiu dentro das prisões brasileiras se coloca como um grande desafio político e analítico. Os grupos que se formaram ao longo das últimas três décadas nas prisões brasileiras, a despeito das expressivas diferenças que guardam entre si, lograram transformar substancialmente as dinâmicas prisionais, situando o sistema carcerário como um hub para a configuração das redes criminais de atuação transnacional (REISS, 1988; DIAS, 2013; 2014; 2017; LESSING, 2017).

As prisões brasileiras atualmente se situam como elementos centrais nas redes criminais que têm o Brasil como lócus de atuação, notadamente, das redes que atuam em torno da economia ilícita das drogas ${ }^{22}$. Neste segmento, se constituem em hub de redes criminais nacionais e transnacionais que se cruzam e se articulam de inúmeras formas com outras redes e atores, desde as prisões até as regiões fronteiriças entre o Brasil e os países produtores de drogas (sobretudo, Bolívia, Colômbia, Peru e Paraguai), abrangendo os mercados consumidores nacionais e os locais que estão situados nas rotas a partir dos quais essas mercadorias são enviadas ao mercado internacional, principalmente, a Europa, via África (PAIVA, 2019; DIAS \& MANSO, 2018; DURÁN-MARTÍNEZ, s/d; KENNEY, 2007).

Já na década de 1980, ao tratar da transição da primeira para a segunda geração do CV, Edmundo Campos Coelho ([2005]1987) apontava as mudanças de seu perfil e os efeitos dessas mudanças: enquanto os fundadores do CV eram predominantemente assaltantes de banco, a partir da segunda geração, e cada vez mais fortemente, a cúpula da facção passou a ser composta de traficantes de drogas. Para o autor, essa mudança configurava uma nova forma de atuação do CV. Os traficantes se caracterizavam pelo seu poder remunerativo dentro das prisões, ou seja, tinham condições de oferecer vanta-

22 Algumas dessas redes de base prisional também atuam em outras modalidades de crimes, tais como roubos a instituições financeiras, cargas, automóveis. 
gens econômicas em troca de lealdade; ao passo que os assaltantes de Banco, na visão do autor, detinham um poder normativo, isto é, estabeleciam normas de comportamento e de conduta. Enquanto os assaltantes tinham sua atuação integralmente voltadas para dentro das prisões, os traficantes canalizavam sua atenção para fora, isto é, para o gerenciamento de seus negócios.

O contexto histórico em torno do qual Coelho ([1987]2005) tece suas reflexões sobre a primeira década do CV reflete, de certo modo, as transformações pelas quais o Brasil passou e, então, antecipa questões que décadas mais tarde se constituirão como nucleares na compreensão das redes criminais e das redes prisionais no país. Antecipa, ainda, a centralidade que cada vez mais assumirão, especialmente no que diz respeito ao tráfico de drogas, as chamadas "facções", que têm no CV o precursor dessas dinâmicas criminais (AMORIM, 1993; COELHO [2005]1987); MISSE, 1998).

Uma diversidade de autores, tais como Forgione (2011); Saviano (2013); Naím (2006), Ziegler (2006), Glenny (2008) e Salamanca e Salcedo-Albarán (2012) - cada um a partir de perspectivas, contextos e enfoques diferentes argumentam que, nas últimas décadas, houve uma transformação profunda na configuração nas dinâmicas do crime organizado em nível internacional, tendo como consequência a integração transnacional das redes de crimes ilícitos: redes de narcotráfico, de tráfico de armas, de tráfico de pessoas e pirataria estariam interconectadas, tornando-se mais complexas e colocando maiores desafios para o seu enfrentamento pelas autoridades estatais ${ }^{23}$. Essa estrutura de organização multiconectada, que ocupa o lugar de arranjos os quais uma vez foram dotados de hierarquia e rigidez ${ }^{24}$, fazem com que sua desarticulação seja mais difícil.

Por outro lado, para compreender a natureza e a dinâmica das redes criminais -, e das redes sociais em geral -, é necessário situá-las em seu contexto próprio que fornece os elementos a partir dos quais são criados os laços de

23 Ao longo da leituras das CPIs, são constatados também relatos em que se averigua essa conectividade com outras formas de crime organizado (ex: tráfico de drogas e exploração grilagem ou, mesmo, tráfico de órgãos). Ainda que não seja objeto desta pesquisa, coadunando-se com o que é aqui afirmado, a CPI da Biopirataria (2004-2006) também constatou que as quadrilhas que traficam animais: "não mexem só com tráfico de animais, mas também com tráfico de drogas e outras ações criminosas” (CÂMARA, 2006b). Haveria um estreitamento de conexões, visando a um ganho de escala, levando os agentes a formarem "associações" para transportar em conjunto drogas e animais.

24 Os autores citam o caso da queda do cartel de Medellín com a morte de Pablo Escobar (19491933). 
confiança e lealdade que conectam os indivíduos uns aos outros. Conforme aponta Von Lampe (2012), o “crime organizado” não opera dentro de um vácuo social, mas interage com seu ambiente. Logo, devemos ter uma compreensão completa dos laços e interações sociais, se quisermos explicá-los. Os laços sociais são fundamentais para estes atores já que eles operam em ambientes relativamente hostis e incertos. Em decorrência da ilegalidade de suas atividades, não contam com a proteção legal e nem com os mecanismos formais de resolução de conflitos e de mediação. Desse modo, os problemas de desconfiança podem ser mitigados quando as transações ilegais estão embutidas nas redes de relações sociais nas quais os vínculos ultrapassam o interesse econômico e assumem dimensões de solidariedade e lealdade.

Nesse sentido, a importância da existência de laços de confiança é essencial para compreender as dinâmicas das redes criminais (VON LAMPE \& JOHANSEN, 2003). Esses autores propõem quatro tipologias de diferentes bases de confiança: i) a individualizada: ou seja, pautada nas relações pessoais entre sujeitos; ii) a baseada na reputação confiável que o sujeito adquire frente a um grupo; iii) a baseada em generalizações - que é a confiança ligada ao pertencimento a um mesmo grupo delinquente, por exemplo, a máfia iv) a abstrata - baseada em sistemas abstratos, ou em sistemas exteriores ao indivíduo, como, por exemplo, a confiança em instituições como o governo e o sistema monetário.

Ainda que os autores salientem que é possível existir cooperação criminosa sem haver relações de confiança, onde há a existência de relações de confiança, a cooperação adquire maior estabilidade e previsibilidade e, portanto, reforça o ciclo da confiança. Os laços familiares - base de confiança individualizada - eram elementos centrais nas atividades de Fernandinho Beira-Mar, conforme foi possível observar nos documentos das CPIs. Já nas dinâmicas criminais que envolvem o PCC, observa-se que, no processo de recrutamento para um indivíduo fazer parte do grupo, ou seja, se tornar irmão, se coloca a necessidade de existência de laços de confiança prévios entre o novo integrante e aqueles que são os fiadores do seu ingresso no grupo, seus padrinhos (DIAS, 2013).

Os compromissos assumidos no batismo garantirá a conformação de relações de confiança cuja base, os autores citados chamam de "generalização"e que consiste justamente naquela que está ligada ao pertencimento do indivíduo a um determinado grupo e que, neste sentido, se direciona ao grupo 
e não ao indivíduo. O elemento comum a esses indivíduos e que permite a construção do vínculo de confiança entre eles através da filiação a um grupo é o encarceramento (SHIMIZU, 2011). A prisão se constitui como locus de produção de vínculos de confiança e, dessa forma, de construção de redes criminais mais estáveis e previsíveis ao conectar indivíduos com diferentes trajetórias criminais em torno de um mesmo repertório discursivo e de oportunidades econômicas mais diversas.

\section{Algumas considerações}

Este trabalho pretende ser apenas o ponto de partida de uma análise mais profunda dos materiais produzidos pelas três CPIs - Narcotráfico, Tráfico de Armas e Sistema Carcerário - a partir dos quais consideramos possível e pertinente delinear os traços e pontos de deslocamento das redes criminais que atuam na economia das drogas ilícitas no Brasil em direção à conformação das prisões como hub dessas redes, por meio das organizações de base prisional, como o PCC, que cada vez assumem maior protagonismo nos mercados ilegais e ampliam sua abrangência local, nacional e transnacional.

Importante ressaltar que a breve síntese dos relatórios que foi apresentada não pretende ir além dos elementos que foram recortados como focos destas reflexões. Nesse sentido, não desconsideramos as diferenças entre as três investigações em termos de seu escopo, tamanho, foco, no perfil dos atores que foram privilegiados, seja para depor como testemunha ou como acusados, nas atividades descritas e na forma de organização de coleta e exposição das informações. Ao contrário, consideramos esses elementos centrais na compreensão das especificidades do trabalho de cada Comissão. Contudo, a reflexão aqui proposta tem um recorte bastante específico - o deslocamento da prisão para uma posição de centralidade na discussão sobre as dinâmicas criminais e, especificamente, as economias ilegais nacionais e transnacionais - a partir do qual perseguimos os elementos presentes no material analisado que nos possibilitaram tecer as linhas de continuidades e descontinuidades entre elas.

Considerando a emergência e a expansão dos grupos criminosos de base prisional, que neste período seguem transbordando os muros das prisões e assumem centralidade no debate sobre segurança pública e violência (DIAS, 2013;, 2017; MANSO \& DIAS, 2017), foi possível verificar que as 
CPIs também refletem o deslocamento da discussão dos mercados ilícitos das drogas para as dinâmicas prisionais que, cada vez mais, se conectam e entrelaçam entre si a partir das redes criminais constituídas nas prisões e a partir das prisões.

A expansão do mercado consumidor de cocaína e maconha, abrangendo todo o território nacional e elevando o país ao segundo lugar do ranking mundial em consumo de cocaína; a consolidação do Brasil como rota de passagem para as mercadorias ilícitas exportadas para a Europa, especialmente, através da África (KENNEY, 2007; GLENNY, 2008; SAVIANO, 2013); a política de encarceramento adotada em boa parte dos Estados brasileiros nas últimas três décadas que intensificou as más condições das prisões (DIAS et, al. 2015; Dias, 2017), fortalecendo as pressões dentro dos cárceres e as demandas por proteção (SKARBECK, 2014) , produzindo novos arranjos sociais e políticos entre a população carcerária. Esses foram os ingredientes fundamentais da conformação de uma dinâmica econômica protagonizada por redes criminais cujo centro nervoso se localiza dentro de prisões brasileiras e se irradia, através de múltiplos pontos de articulação, até as regiões de fronteira, ultrapassando as delimitações do espaço nacional, alcançando visibilidade e protagonismo em países vizinhos, como Paraguai e Bolívia. Isto é, alcançando a dimensão transnacional que, nas últimas décadas, tem sido apontada como um elemento fundamental da economia ilícita mundial (ZIEGLER, 2003; GLENNY, 2008; NAIM, 2006; MAZUR, 2009; GRILLO, 2012; SOARES, 2012; SAVIANO, 2013; DEMORI, 2016).

O fato de que a primeira CPI tem como foco de investigação o "narcotráfico" e a terceira, o "sistema carcerário", indica a crescente importância que cada um desses temas vai assumindo no país e, ainda mais, o entrelaçamento entre esses fenômenos. Nesse sentido, nosso argumento é que a própria sequência das três CPIs - Narcotráfico, Tráfico de Armas e Sistema Carcerário - mais do que responder a problemas específicos e desconexos, de certa forma, acompanha a dinâmica própria do fenômeno ocorrido no Brasil em que as prisões se constituem em hub criminal, se conectando diretamente e de diversas formas às redes ilícitas transnacionais. 


\section{Referências}

ADORNO, Sérgio.; DIAS, Camila C. N. (2016), "Cronologia dos "Ataques de 2006" e a nova configuração de poder nas prisões na última década”. Revista Brasileira de Segurança Pública. Vol. 10, n.2, 118-132, ago/set.

ALBINI, Joseph L. (1997), “Donald Cressey's contributions to the study of organized crime: an evaluation”. In: RYAN, P.J; RUSH, G. E. (Ed.). Understanding organized crime in global perspective: a reader. Sage Publications, US, p. 16-25.

AMORIM, Carlos. (1993), Comando Vermelho - A história secreta do crime organizado. Rio de Janeiro: Record.

BRASIL. Ministério da Integração Nacional, (2009), Faixa de Fronteira: Programa de Promoção ao Desenvolvimento da Faixa de Fronteira. Brasília.

BRASIL. (2004), Decreto n. 5015 de 12 de Março de 2004. Promulga a Convenção das Nações Unidas contra o Crime Organizado Transnacional. Diário Oficial da União.

CÂMARA aprova CPI para apurar tráfico de arma. Folha de São Paulo. São Paulo. Cotidiano 4, mar de 2005. Disponível em: https://www1.folha.uol. com.br/fsp/cotidian/ff0403200532.htm

CÂMARA DOS DEPUTADOS. (2008), Relatório da Comissão Parlamentar de Inquérito Destinada a Investigar o Sistema Carcerário Brasília.

- (2006b), Relatório da Comissão Parlamentar de Inquérito Destinada a Investigar o Avanço o Tráfico de Armas. Brasília.

. (2006b) Relatório da Comissão Parlamentar de Inquérito Destinada a Investigar o Avanço o Tráfico de Animais e Plantas Silvestres Brasileiros, a Exploração e Comércio Ilegal de Madeira e a Biopirataria no País. Brasília.

- (2000), Relatório da Comissão Parlamentar de Inquérito Destinada a Investigar o Avanço e a Impunidade do Narcotráfico. Brasília.

CLEMMER, Donald. (2011), The prison community. Nova York: Rinehart \& Company.

COELHO, Edmundo C. 2005 [1987]), Oficina do diabo e outros estudos sobre criminalidade. Rio de Janeiro/São Paulo: Editora Record.

DEMORI, Leandro. (2016), Cosa nostra no Brasil: a história do mafioso que derrubou o império. São Paulo: Companhia das Letras.

DIAS, Camila C. N. (2014), Disciplina, controle social e punição: o entrecruzamento das redes de poder no espaço prisional. Revista Brasileira de Ciências Sociais, v. 29, p. 113-127. 
. (2008), PCC: hegemonia nas prisões e monopólio da violência. São Paulo: Ed. Saraiva.

. (2011a) Estado e PCC em meio às tramas do poder arbitrário nas prisões. Tempo Social, revista de sociologia da USP, v. 23. Disponível em: n. http://www.scielo.br/pdf/ts/v23n2/v23n2a09.pdf.

- (2011b), Da pulverização ao monopólio da violência: expansão e consolidação do Primeiro Comando da Capital (PCC) no sistema carcerário paulista. São Paulo, 386 pp. Tese de doutorado. Faculdade de Filosofia, Letras e Ciências Humanas da Universidade de São Paulo.

- (2009a), "Ocupando as brechas do direito formal: o PCC como instância alternativa de resolução de conflitos”. Dilemas, Rio de Janeiro, v. 4, n.2 p.83-105, abr.-jun.

. (2009b), "Efeitos simbólicos e práticos do Regime Disciplinar Diferenciado (RDD) na dinâmica prisional”. Revista Brasileira de Segurança Pública. São Paulo, ano 3: 128-144, ago.-set.

.; BRITO, Josiane S.. ; KULLER, Laís B. F; GOMES, Mayara S. (2015), O encarceramento em massa como política de segurança. In: Teoria $\&$ Debate, São Paulo, p. 1-15, 16 jun.

DURÁN-MARTINEZ, Angélica. (s/d.). "Illicit Drug and Organized Crime in Latin America: New Scholarship and the Future of Alternative Policies”. Draft.

FELTRAN, Gabriel, (2012), S. Governo que produz crime, crime que produz governo: o dispositivo de gestão do homicídio em São Paulo (1992 - 2011). Revista Brasileira de Segurança Pública, v. 6, n. 2, São Paulo, 232$255 \mathrm{ago} / \mathrm{set}$.

GALLO, Fernanda A. As formas do Crime Organizado.Tese (doutorado) Universidade Estadual de Campinas. Instituto de Filosofia e Ciências Humanas. Campinas, 2014. Disponível em: http://www.repositorio.unicamp.br/ handle/REPOSIP/281284.

. (2011-2012) Tutorial de redes e um estudo de caso sobre "redes criminais”. Revista USP. São Paulo, n. 92, p. 74-85, dez./fev.

GLENNY, Misha. (2008), MacMafia: crime sem fronteiras. São Paulo: Companhia das Letras.

GRILLO, Christoph. (2013), Coisas da Vida no Crime: Tráfico e roubo em favelas cariocas. Tese (Doutorado em Ciências Humanas - Antropologia Cultural) Universidade Federal do Rio de Janeiro, Instituto de Filosofia e Ciências Sociais, Programa de Pós-Graduação em Sociologia e Antropologia, Rio de Janeiro.

GRILLO, Ioan. (2012), El narco: en el corazón de la insurgencia criminal mexicana. Barcelona: Tendencias. 
IHRC - INTERNATIONAL HUMAN RIGHTS CLINIC. (2011), São Paulo Sob Achaque: Corrupção, Crime Organizado e Violência Institucional em Maio de 2006. International Human Rights Clinic at Harvard Law.

KENNEY, Michael. The architecture of Drug Trafficking: network forms of organisation in the Colombian Cocaine Trade. Global Crime, 8:3, pp. 233-259.

MÃES DE MAIO. (2011), Mães de Maio: Do Luto à Luta. Movimento Mães de Maio. São Paulo. Nós por nós.

MANSO, Bruno Paes; DIAS, Camila C. N. (2018), A Guerra: a ascensão do PCC e o mundo do crime no Brasil. São Paulo: Todavia.

MAZUR, Robert. (2009), O infiltrado: minha vida secreta nos bastidores da lavagem de dinheiro do Cartel de Medellín. Curitiba: Nossa Cultura.

NAÍM, Moisés. (2006), Ilícito: o ataque da pirataria, da lavagem de dinheiro e do tráfico à economia global. Rio de Janeiro: Jorge Zahar Editor.

PAIVA, Luiz Fábio. S. (2019), As dinâmicas do mercado ilegal de cocaína na tríplice fronteira entre Brasil, Peru e Colômbia. Revista brasileira de Ciências Sociais, São Paulo, v. 34, n. 99, e349902.

PAOLI, Leticia. (2002), “The Paradoxes of Organized Crime”. Crime, Law $\mathcal{E}$ Social Change 37, p. 51-97.

. (2017), "What is the link between organized crime and drug trafficking?”. Rausch, 6. Jahrgang, 4-2017, pp. 181-189.

PASTORAL CARCERÁRIA NACIONAL: coordenação de obra coletiva. (2014) José de Jesus Filho e Amanda Hildebrand Oi, "Prisões privatizadas no Brasil em debate”, São Paulo: ASAAC, .

POSSAS, Mariana T; ROCHA, Thiago T. (2014), "A onça comeu o suspeito”: reflexões sobre o rule of law no Acre entre os anos 1980 e 2000. Lua Nova, São Paulo, n. 91, p. 229-268, Apr. Disponível em: < http://www.scielo.br/ scielo.php?script =sci_arttext\&pid $=$ S0102-64452014000100009\&lng $=$ en\& $\mathrm{nrm}=\mathrm{iso}>$. Accesso em: 17 Apr. 2019. http://dx.doi.org/10.1590/S010264452014000100009 .

RODRIGUES, Thiago M. S. (2002) A infindável guerra americana: Brasil, EUA e o narcotráfico no continente. São Paulo Perspec, São Paulo, v. 16, n. 2, p. 102-111, June.

ROGOVIN, Charles H. \& MARTENS, Frederick T. (1997), "The evil that men do”. In: RYAN, Patrick J. ; RUSH, George E. (Ed.). Understanding organized crime in global perspective: a reader. Sage Publications, US, pp. 26-36.

SALAMANCA, Luis Jorge G \& SALCEDO-ALBARÁN, Eduardo. (2016), Networks of Evil: Transnational criminal cartels, still poorly understood, are undermining order around the world. Here's how they can be disrupted. City Journal. Spring. 
- (2012), Narcotráfico, corrupción y Estados: cómo las redes ilícitas han reconfigurado las instituciones en Colombia, Guatemala y México. Random House.

SALLA, Fernando. (2007). De Montoro a Lembo: As políticas penitenciárias em São Paulo. Revista Brasileira de Segurança Pública, São Paulo, ano 1, n. 1, p. 72-90.

. (2006). As rebeliões nas prisões: novos significados a partir da experiência brasileira. Sociologias, Porto Alegre, ano 8, n. 16, jul.-dez., p. 274307.

- (2003). Os impasses da democracia brasileira: O balanço de uma $\overline{\text { década }}$ de políticas para as prisões no Brasil. Lusotopie, p. 419-35.

SAVIANO, Roberto. (2013), Zerozerozero. São Paulo: Companhia das Letras.

SHIMIZU, Bruno. (2011), Solidariedade e gregarismo nas facções criminosas: um Estudo Criminológico à luz da Psicologia das massas. São Paulo: IBCCRIM.

SINHORETTO, Jacqueline; SILVESTRE, Giane.; MELLO, Felipe A. L. (2013), O encarceramento em massa em São Paulo. Tempo soc., São Paulo, v. 25, n. 1, p. 83-106.

SKARBECK, David. The social order of the underworld: how prison gangs govern the American Penal System. New York: Oxford University Press.

SOARES, Luís Eduardo. (2012), Tudo ou nada: a história d o brasileiro preso em Londres por associação ao tráfico de duas toneladas de cocaína. Rio de Janeiro: Editora Nova Fronteira.

SYKES, Gresham M. (1974), The society of captives: A study of a maximum security prison. Princeton: Princeton University Press.

UNITED NATIONS OFFICE OF DRUGS AND CRIME. (2019), Relatório Mundial sobre Drogas 2019. United Nations, June 2019. A Disponível em: https:// wdr.unodc.org/wdr2019/

VASCONCELOS, Beto F. M.; CARDOZO, José Eduardo M. .; PEREIRA, Marivaldo C.; DE VITTO, Renato C. P.; (2018). Questão Federativa, Sistema Penitenciário e Intervenção Federal. In: Revista Culturas Jurídicas. Vol. 5. Núm. 10: jan./abr.

VON LAMPE, Klaus. (2012), As Dimensões Interdisciplinares do Estudo do Crime Organizado. Estud. sociol., Araraquara, v.17, n.33, p.401427.

VON LAMPE, Klaus; JOHANSEN, Per Ole. (2003), “Criminal Network and Trust”, in European Society of Criminology, Helsinki. Disponível em: http:// www.organized-crime.de/criminalnetworkstrust.htm. 
ZAFFARONI, Eugenio Raul. (1996). "Crime organizado: uma categorização frustrada”.In: ano 1, n.1. . Discursos Sediciosos. Rio de Janeiro: Relume-dumará,

ZIEGLER, Jean. (2003), Os senhores do crime: as novas máfias contra a democracia. Rio de Janeiro/São Paulo: Editora Record.

Submetido em 20 de abril. 2019

Aprovado em 18 de junho 2019

\section{(cc) $\mathrm{BY}$}

Licenciado sob uma Licença Creative Commons Attribution 3.0 